\title{
Hornerin deposits in neuronal intranuclear inclusion disease: direct identification of proteins with compositionally biased regions in inclusions
}

\author{
Hongsun Park' , Tomoyuki Yamanaka ${ }^{1,2}$, Yumiko Toyama ${ }^{3}$, Atsushi Fujita ${ }^{4}$, Hiroshi Doi ${ }^{5}$, Takashi Nirasawa ${ }^{6}$, \\ Shigeo Murayama ${ }^{7}$, Naomichi Matsumoto $^{4}$, Tomomi Shimogori ${ }^{8}$, Masaya Ikegawa ${ }^{3}$, Matti J. Haltia ${ }^{9}$ and \\ Nobuyuki Nukina ${ }^{1,10^{*}}$ (1)
}

\begin{abstract}
Neuronal intranuclear inclusion disease (NIID) is a neurodegenerative disorder, characterized by the presence of eosinophilic inclusions (NIIs) within nuclei of central and peripheral nervous system cells. This study aims to identify the components of NIIs, which have been difficult to analyze directly due to their insolubility. In order to establish a method to directly identify the components of NIls, we first analyzed the huntingtin inclusion-rich fraction obtained from the brains of Huntington disease model mice. Although the sequence with expanded polyglutamine could not be identified by liquid-chromatography mass spectrometry, amino acid analysis revealed that glutamine of the huntingtin inclusion-rich fraction increased significantly. This is compatible with the calculated amino acid content of the transgene product. Therefore, we applied this method to analyze the Nlls of diseased human brains, which may have proteins with compositionally biased regions, and identified a serine-rich protein called hornerin. Since the analyzed NII-rich fraction was also serine-rich, we suggested hornerin as a major component of the NIIs. A specific distribution of hornerin in NIID was also investigated by Matrix-assisted laser desorption/ionization imaging mass spectrometry and immunofluorescence. Finally, we confirmed a variant of hornerin by whole-exome sequencing and DNA sequencing. This study suggests that hornerin may be related to the pathological process of this NIID, and the direct analysis of NIIs, especially by amino acid analysis using the NII-rich fractions, would contribute to a deeper understanding of the disease pathogenesis.
\end{abstract}

Keywords: NIID, Neuronal intranuclear inclusion, Hornerin, Amino acid analysis, Compositionally biased region, Low sequence complexity

\footnotetext{
*Correspondence: nnukina@mail.doshisha.ac.jp

${ }^{1}$ Laboratory of Structural Neuropathology, Doshisha University

Graduate School of Brain Science, 1-3 Miyakodanitatara, Kyotanabe-shi, Kyoto 610-0394, Japan

Full list of author information is available at the end of the article
}

\section{Introduction}

Neuronal intranuclear inclusion disease (NIID) is a slowly progressive neurodegenerative disorder, characterized pathologically by eosinophilic inclusions within the nuclei of central, peripheral and autonomic nervous system cells. The first case of the disease was described in 1968 [1], and since then, a number of cases have been reported, based on autopsy findings [2-4]. Antemortem diagnosis has been difficult because NIID shows variable original author(s) and the source, provide a link to the Creative Commons licence, and indicate if changes were made. The images or other third party material in this article are included in the article's Creative Commons licence, unless indicated otherwise in a credit line to the material. If material is not included in the article's Creative Commons licence and your intended use is not permitted by statutory regulation or exceeds the permitted use, you will need to obtain permission directly from the copyright holder. To view a copy of this licence, visit http://creativecommons.org/licenses/by/4.0/. The Creative Commons Public Domain Dedication waiver (http://creativeco mmons.org/publicdomain/zero/1.0/) applies to the data made available in this article, unless otherwise stated in a credit line to the data. 
clinical manifestations, including cognitive impairment, parkinsonism and neuropathy at varying ages of onset, ranging from infancy to late adult age [5]. Recently, NIID has been considered to be not only clinically but also genetically heterogeneous [6].

Neuronal intranuclear inclusions (NIIs) are thought to be formed due to an excessive accumulation of proteins within the nucleus [7]. Apart from NIID, they may be associated with various other neurodegenerative diseases, caused by the expansion of trinucleotide repeats [8]. For example, nine neurodegenerative diseases, including Huntington disease (HD), spinal and bulbar muscular atrophy, dentatorubral-pallidoluysian atrophy and six autosomal dominant forms of spinocerebellar ataxia (SCA1, 2, 3, 6, 7, and 17), are caused by expansions of CAG repeats, encoding expanded polyglutamine tracts, and have NIIs containing the respective pathogenic protein [9]. Thus, the inclusions of these diseases are supposed to be composed of the proteins with low complexity regions (LCRs). Even cytoplasmic inclusions can be formed by accumulation of misfolded proteins, such as a-synuclein in Parkinson disease (PD) or tau protein in Alzheimer disease (AD), which are thought to contain LCRs in their sequences. Such proteins are known as intrinsically disordered proteins (IDPs), characterized by the presence of intrinsically disordered regions [10]. Unlike folded domains, intrinsically disordered regions do not adopt stable secondary structures, and the LCRs exhibit compositional bias towards a small set of amino acids [11], causing proteins to misfold. Other expanded repeats can be translated into proteins containing a pathogenic stretch of repeated amino acids by a novel mechanism called repeat-associated non-AUG (RAN) translation [12], and these proteins could contain compositionally biased amino acids.

In 2011, Sone et al. [13] reported that skin biopsies are useful for the antemortem diagnosis of NIID, and skin biopsies have contributed to an increased number of patients diagnosed with NIID. Later, the disease of a number of NIID patients diagnosed by skin biopsy was shown to be caused by the mutant NOTCH2NLC gene with expanded GGC or CGG repeats $[14,15]$. The mutant NOTCH2NLC gene expressing 69 GGC repeats is translated into NOTCH2NLC-polyglycine protein [16]. Furthermore, GGC repeats of NOTCH2NLC (N2C) protein have been thought to be embedded in a small upstream open reading frame ( $\mathrm{UORF}$ ) located ahead of the main N2C ORF, encoding a small protein, uN2C, with an expanded polyglycine stretch (uN2CpolyG) in this form of NIID [17].

Unlike these NIID cases, which were mostly found in people of Asian origin [6], the NIID brain sample used in this study showed different features. This unique NIID case [2], one of concordant twins, had juvenile-onset without any identified expanded repeats such as CAG or GGC, and the NIIs found in this case were autofluorescent and showed a fibrillar ultrastructure $[2,6]$. In addition, an infantile NIID case has been reported with no expanded repeats. Skin biopsy had not been helpful [18]. This case provides additional evidence suggesting genetic heterogeneity of NIID and implies that analyses of NOTCH2NLC GGC repeats and/or skin biopsy testing may not reliably diagnose the disease in suspected patients. Although studies have been focused mainly on the genes related to NIIs pathology, little remains known about the components of NIIs and the pathogenesis of NIID. However, because the deposited protein is not always a mutant protein, as shown by e.g. $\mathrm{A} \beta$ deposition in presenilin mutations, it is important to identify the deposited protein to reveal the disease cascade.

It has been considered that the composition of NIIs can be distinct in different diseases, but this has been difficult to analyze directly, due to the insolubility of the proteins. In this study, using an NIID brain sample [2], we investigated the components of NIIs directly by several proteomic analyses, including liquid-chromatography mass spectrometry (LC-MS/MS), Matrix-assisted laser desorption/ionization imaging mass spectrometry (MALDIIMS), shotgun proteomics and amino acid analysis, and finally identified hornerin as the main component of the NIIs in this case.

\section{Materials and methods HD190QG transgenic mice}

All surgical procedures and experiments were approved by the Doshisha university ethics committee and the RIKEN ethics committee. All animal experiments were performed in accordance with the guidelines approved by the Doshisha university and RIKEN Animal Experiments Committee. All experiments were carried out in accordance with the approved ethical guidelines and regulations. Huntington disease model mice expressing the first exon of human huntingtin with an expanded polyglutamine fused with an enhanced green fluorescent protein (EGFP) under the control of the human huntingtin promoter were generated as described previously [19]. 24-week-old HD190QG male mice and the wild type (WT) littermates were used in this study.

\section{Human brain samples}

The NIID brain sample for this study was reported previously [2]. The brain was removed $3 \mathrm{~h}$ postmortem and kept at $-80^{\circ} \mathrm{C}$. Control 1 (55 years old, male) and Control 2 (50 years old, female) brains were approved by Doshisha university. Human cortical specimens for imaging mass spectrometry were also obtained from the Brain 
Bank at Tokyo Metropolitan Institute of Gerontology. Brains were removed, processed and stored at $-80{ }^{\circ} \mathrm{C}$ within $8 \mathrm{~h}$ postmortem. Patients were placed in a cold room $\left(4^{\circ} \mathrm{C}\right)$ within $2 \mathrm{~h}$ after death. All brains registered at the Brain Bank came with written informed consents for their use in medical research from the patients or their families. Brain specimens were taken from the occipital cortex of AD and age-matched control patients as well as NIID. This study was approved by the ethics committee at Doshisha University and Tokyo Metropolitan Geriatric Hospital.

\section{Isolation of NIls}

Mouse brains were homogenized in 9\% sucrose in a homogenization buffer [ $9 \%$ sucrose in 2 mM EDTA (pH 8.0)/25 mM Tris-HCl (pH 8.0)/5 mM DL-Dithiothreitol (DTT)] with a protease inhibitor, cOmplete ${ }^{\mathrm{TM}}$ (Roche), using Potter-Elvehjem Tissue Grinders. Brain lysate was then centrifuged at $12,000 \times g$ for $10 \mathrm{~min}$ at $4{ }^{\circ} \mathrm{C}$, and the pellet (P1) was resuspended in a homogenization buffer without sucrose. The solution was filtered with a $40 \mu \mathrm{m}$ cell strainer (Falcon), and the flow-through was collected as P1 solution. The P1 solution $(1 \mathrm{mg} / \mathrm{ml})$ was then treated with $1 \%$ sarkosyl solution at room temperature for $1 \mathrm{~h}$ while rotating. The solution was ultracentrifuged at $153,725 \times g\left(50,000 \mathrm{rpm}\right.$; Optima $^{\mathrm{TM}}$ MAX-XP Ultracentrifuge, TLA-55 rotor, Beckman) for $30 \mathrm{~min}$ at $4{ }^{\circ} \mathrm{C}$. The pellet (P2) was washed with $50 \mathrm{mM}$ Tris $-\mathrm{HCl}$ $(\mathrm{pH} 7.6)$ and ultracentrifuged again at $153,725 \times \mathrm{g}$ for $30 \mathrm{~min}$ at $4{ }^{\circ} \mathrm{C}$. After resuspending the pellet (P3) with $50 \mathrm{mM}$ Tris- $\mathrm{HCl}$ (pH 7.6) using a glass homogenizer, P3 solution was treated with nuclease solution [Micrococcal nuclease (1:400, Thermo Scientific), $5 \mathrm{mM} \mathrm{CaCl}_{2}, 50 \mathrm{mM}$ Tris- $\mathrm{HCl}(\mathrm{pH} 7.6)]$ for $30 \mathrm{~min}$ at $37^{\circ} \mathrm{C}$ until the nucleic acids were digested. The reaction was stopped by adding $20 \mathrm{mM}$ EGTA ( $\mathrm{pH} 7.6$ ), and the solution was ultracentrifuged at $153,725 \times g$ for $30 \mathrm{~min}$ at $4{ }^{\circ} \mathrm{C}$. After the nuclease treatment, the pellet (P4) was resuspended with $200 \mu \mathrm{l}$ of homogenization buffer, treated with $2 \%$ sodium dodecyl sulfate (SDS)/10 mM DTT at $100{ }^{\circ} \mathrm{C}$ for $5 \mathrm{~min}$, followed by ultracentrifuging at $153,725 \times g$ for $30 \mathrm{~min}$ at $20{ }^{\circ} \mathrm{C}$. The supernatant was collected as the SDS-soluble fraction. The SDS-insoluble pellet was treated with $70 \%$ formic acid (FA), sonicated for $30 \mathrm{~s}$ twice (Bioruptor sonicator, BMBio) and incubated at $37{ }^{\circ} \mathrm{C}$ for $1 \mathrm{~h}$. After evaporating in a vacuum, the remaining proteins, i.e., the FA-treated fraction, were considered to include the components of NIIs.

The NII-rich fractions of human brains were obtained directly from NIID and the control brains using the same protocol of mouse brain nuclei fractionation but with an additional SDS-wash after treating the resuspended
P4 fraction with $2 \%$ SDS/10 $\mathrm{mM}$ DTT to remove the remaining SDS-soluble proteins in the tube.

\section{Antibodies}

We used the following primary antibodies: EM48 (1:500 for Western blot (WB), 1:1,000 for immunofluorescence (IF), MAB5374, Chemicon), anti-GFP (1:1,000 for WB and IF, 598, MBL), anti-ubiquitin (1:1,000 for WB and IF, MAB1510, Merck Millipore) and anti-hornerin (1:500 for WB, HPA-31469, Sigma-Aldrich) antibodies. AntiHRNR (HP) antibody used for IF (1:1000) was designed to detect human $\mathrm{HRNR}_{968-1349}$ (made in our laboratory with CosmoBio).

The following secondary antibodies were used: HRPconjugated mouse IgG (1:2,000 for WB, GE healthcare), HRP-conjugated rabbit IgG (1:2,000 for WB, GE healthcare), Alexa Flour ${ }^{\circledR} 546$ anti-mouse IgG (1:300 for IF, Life technologies), Alexa Fluor ${ }^{\circledR} 594$ anti-rabbit IgG (1:300 for IF, Invitrogen), Alexa Fluor ${ }^{\circledR} 647$ anti-mouse IgG (1:300 for IF, Invitrogen) and Alexa Fluor ${ }^{\circledR} 647$ anti-rabbit IgG (1:300 for IF, Life technologies) antibodies.

\section{Immunofluorescence}

The smears of each fraction were dried overnight on a slide glass and blocked in $500 \mu \mathrm{l}$ of blocking buffer containing $0.1 \%$ TritonX-20 and $2.5 \%$ goat serum in Tris Buffered Saline with $0.1 \%$ Tween 20 (TBST) for $30 \mathrm{~min}$ at room temperature. After the incubation with primary antibodies diluted in $0.1 \%$ bovine serum albumin (BSA)/ TBST overnight at $4{ }^{\circ} \mathrm{C}$., the samples were incubated with fluorescent secondary antibodies at room temperature for $2 \mathrm{~h}$.

The brain sections ( $10 \mu \mathrm{m}$-thick) were washed in phosphate buffered saline (PBS) for $10 \mathrm{~min}$ and fixed with $4 \%$ paraformaldehyde in phosphate buffered saline (PFA/ PBS) for $5 \mathrm{~min}$ at room temperature. After heat activation in $0.1 \%$ citrate buffer $(\mathrm{pH} 6.0)$ at $121{ }^{\circ} \mathrm{C}$ for $5 \mathrm{~min}$, the brain sections were cooled down on ice for $10 \mathrm{~min}$, washed with MilliQ and TBST sequentially and blocked in $0.1 \% \mathrm{BSA} / \mathrm{TBST}$ at room temperature for $1 \mathrm{~h}$. After the primary antibody incubation diluted in TBST overnight at $4{ }^{\circ} \mathrm{C}$, the brain sections were incubated with fluorescent secondary antibodies at room temperature for $2 \mathrm{~h}$.

The samples were mounted with VECTASHIELD ${ }^{\circledR}$ mounting medium for fluorescence with DAPI (H-1200, Vector Laboratories), and the images were taken with BIOREVO BZ-9000 (KEYENCE).

\section{Western blot}

Equal amounts of P1 solution, SDS-soluble and FAtreated fractions were re-solubilized in SDS containing Laemmli buffer. The proteins were separated in a 5-20\% SDS-polyacrylamide gel (e-PAGEL ${ }^{\circledR}$, E-T520L, 
ATTO) and transferred to polyvinylidene difluoride membranes (Immobilon ${ }^{\circledR}-\mathrm{P}$ Transfer Membrane, Merck Millipore). The membranes were blocked with $2.5 \%$ goat serum/TBST and incubated with primary antibodies diluted with $2.5 \%$ goat serum/TBST at $4{ }^{\circ} \mathrm{C}$, overnight. The membranes were washed in TBST for 10 min twice and incubated in secondary antibodies diluted with $2.5 \%$ goat serum/TBST for $1 \mathrm{~h}$, at room temperature. The immunoreactive proteins were visualized with the application of the substrate for enhanced chemiluminescence (Luminata, Merck Millipore). The signals were acquired using ImageQuant LAS-4000 (GE Healthcare).

\section{Protein digestion and LC-MS/MS}

Protein tryptic digestion was performed with the Filter-aided Sample Preparation (FASP) method [20]. Samples were mixed with UA solution ( $8 \mathrm{M}$ Urea in $100 \mathrm{mM}$ Tris- $\mathrm{HCl}, \mathrm{pH}$ 8.0) in filter units (molecular weight cut-off $30 \mathrm{kDa}, \mathrm{PT}-1007$, Aproscience) and centrifuged at $14,000 \times g$ for $15 \mathrm{~min}$ at room temperature, followed by the addition of IAA solution $(0.05 \mathrm{M}$ iodoacetamide in UA). The samples were then incubated for $20 \mathrm{~min}$ in the dark at room temperature and filtered by centrifuging them at $14,000 \times g$ for $10 \mathrm{~min}$. After the centrifugation, $100 \mu \mathrm{l}$ of UA was added to the filter, followed by centrifugation at $14,000 \times g$ for $15 \mathrm{~min}$. This step was repeated twice. The proteins trapped on the filters were washed with AmBic solution (50 $\mathrm{mM}$ ammonium bicarbonate in MilliQ) three times, and the residual proteins were enzymatically digested by $40 \mu \mathrm{l}$ of $0.2 \mu \mathrm{g} / \mu \mathrm{l}$ modified trypsin (V511A, Promega) in AmBic solution (enzyme to protein ratio 1: 100) overnight at $37^{\circ} \mathrm{C}$. The digested proteins were collected by centrifuging at $14,000 \times g$ for $10 \mathrm{~min}$ after adding a total of $80 \mu \mathrm{l} \mathrm{AmBic}$ solution and $50 \mu \mathrm{l}$ of $0.5 \mathrm{M} \mathrm{NaCl}$ to the filter units. The filtrates were then applied to the LC-MS/MS system.

In-gel digestion was performed using the Thermo Scientific ${ }^{\mathrm{TM}}$ In-Gel Tryptic Digestion Kit $(89,871$, ThermoScientific) in order to obtain and identify peptides of interest stained by Coomassie Brilliant Blue (CBB). The digested proteins were analyzed by LC-MS/MS.

To obtain MS/MS spectrum data of the peptides, the digested peptides were separated by EASY-nLC 1000 (Thermo Fisher Scientific) and ionized with nano-ESI, followed by analyzation using a QExactive hybrid quadrupole-orbitrap mass spectrometer (Thermo Fisher Scientific). Based on this peptide information, proteins were identified using Proteome Discoverer version 2.4 (PD2.4, Thermo Fisher Scientific) with the MASCOT search engine software (Matrix Science) [21].

\section{MALDI-IMS and LC-TIMS-MS/MS}

Autopsied brains were kept in a deep freezer before experimentation began. $10 \mu \mathrm{m}$ cryosections were cut and transferred to Indium-Tin-Oxide (ITO) coated glass slides. For proteomic imaging, slides were washed with $70 \%$ to $100 \% \mathrm{EtOH}$, Carnoy's solution (EtOH: Chloroform: Acetic acid =6: 3: 1), and $0.1 \%$ Trifluoroacetic acid (TFA). Tissue sections were sprayed with CHCA ( $\alpha$-cyano-4-hydroxycinnamic acid, $10 \mathrm{mg} / \mathrm{ml}$ ) in $70 \%$ acetonitrile $(\mathrm{ACN})$ containing 1\% TFA using an automated sprayer (TM-Sprayer ${ }^{\mathrm{TM}}$, HTX Technologies, Carrboro, NC, USA). Mass spectra were measured by rapiflex tissuetyper (Bruker Daltonics) with a spatial resolution of $20 \mu \mathrm{m}$. For Protein ID experiments, trypsin solution (25 ng/ $\mu \mathrm{l}$, in $20 \mathrm{mM} \mathrm{NH4HCO3aq,} \mathrm{pH} 7.5-8.5$ ) was sprayed at room temperature and incubated for $2 \mathrm{~h}$, at $50{ }^{\circ} \mathrm{C}$. Peptide extraction from brain tissue samples was performed with $25-50 \mu \mathrm{l}$ of $0.1 \%$ TFA onto the tissues and peptide extracts were stored at $-80{ }^{\circ} \mathrm{C}$ for LCTIMS-MS/MS analysis (timsTOF Pro, Bruker Daltonics). MALDI-IMS data were obtained and analyzed using the flexImaging 5.0 and SCiLS Lab 2018b. For proteomic analysis, PEAKS Studio 8.5, ProteinScape and MASCOT software were employed [22].

\section{Amino acid analysis}

SDS-insoluble fractions of HD190QG mouse brains and human brains were hydrolyzed in $6 \mathrm{M} \mathrm{HCl}$ and $4 \mathrm{~N}$ Methanesulfonic acid (MSA), respectively. After the hydrolysis at $110{ }^{\circ} \mathrm{C}$ for $20 \mathrm{~h}, 4 \mathrm{M} \mathrm{NaOH}$ was added to neutralize the MSA. The derivatives were detected using the ninhydrin method to prevent 3-(2-aminoethyl) indole from disturbing the AQC-amino acid chromatogram. The products were detected by High Speed Amino Acid Analyzer, L-8900 (Hitachi High-Technologies). Chromatograms were not normalized in the MSA hydrolysis.

\section{Whole-exome sequencing and repeat analysis of NOTCH2NLC}

To identify the pathogenic variant, we performed wholeexome sequencing of genomic DNA extracted from the patient's brain. Genomic DNA was processed using the SureSelect Human All Exon Kit v5 (Agilent Technologies, Santa Clara, CA) and sequenced on an Illumina HiSeq 2500 with 101-bp paired-end reads. Alignment, variant calling and annotation were performed using Novoalign (http://www.novocraft.com/), Picard (http://picard. sourceforge.net/), Genome Analysis Toolkit (https://www. broadinstitute.org/gatk/index.php) and ANNOVAR(http:// www.openbioinformatics.org/annovar/) as described previously [23]. Single nucleotide variants (SNVs) and insertion/ deletions (indels) were extracted based on information 
regarding rare variants with a minor allele frequency $<1 \%$ in dbSNP137, located in exons or splice sites (within $10 \mathrm{bp}$ of the boundaries).

Repeat-primed PCR for detecting GGC expansions in NOTCH2NLC and fluorescence amplicon length analysis for determining the GGC expansion length in NOTCH2NLC were performed as previously described [14]. Library preparation for long-read sequencing was performed using DNA ligation kit (SQK-LSK109, Oxford Nanopore Technologies, Oxford, UK) after shearing genomic DNA with g-TUBE (Covaris, Woburn, MA, USA), according to the manufacturer's instructions. This library was sequenced on PromethION with a PRO-002 flow cell (R9.4.1, Oxford Nanopore Technologies). Basecalling and fastq file conversion were performed with MinKNOW v1.14.0 (Oxford Nanopore Technologies). Reads were aligned to the human reference genome hg38 using LAST (https://gitlab.com/mcfrith/last) [24], and the tandem repeat number was evaluated using tandemgenotypes v1.1.0 (https://github.com/mcfrith/tandemgenotypes) [25].

\section{DNA sequencing}

Genomic DNA of NIID, Control 1 and Control 2 brains as well as HeLa and HEK293T cells were prepared as templates for polymerase chain reaction (PCR) using two primers, CATCTAGGAGCGAACAACATGG and ATA GCCAGAAGACTGACTTGAGC, to amplify 446 bp hornerin sequence including the variant site. The PCR products were then subjected to electrophoresis with a $2 \%$ agarose gel, and the bands were excised and purified using Wizard ${ }^{\circledR}$ SV Gel and PCR Clean-Up System. The purified PCR product was treated with BigDye ${ }^{\circledR}$ Terminator v3.1 Cycle Sequencing Kit (Thermo Fisher Scientific), followed by ethanol precipitation. The resulting PCR products were dissolved in highly deionized formamide and sequenced.

\section{Results}

\section{The NII-rich fraction was obtained from HD model mouse} brains

To establish a novel method for directly identifying the NII components, we first examined whether glutamine increased in huntingtin inclusions obtained from the brains of HD model mice. We used HD190QG transgenic mice which express the first exon of huntingtin (N-terminal huntingtin: nHTT) with an additional expanded polyglutamine fused with an EGFP (nHTT-EGFP) under the control of the human huntingtin promoter $[19,26]$. NIIs were isolated from the brains of 24-week-old HD190QG transgenic mice (Fig. 1a). The nuclear fractions from brain homogenates were treated with $1 \%$ sarkosyl solution and nuclease, followed by ultracentrifugation, in order to solubilize other proteins from the inclusion bodies as well as to degrade nucleic acids in the fraction [27]. By observing the smears of P1 and P4 fractions stained with DAPI, we confirmed that the chromatins in the P4 fractions were well degraded (Fig. 1b). To investigate whether nHTT inclusions remained in $\mathrm{P} 4$ after certain treatments, immunofluorescence staining was performed with EM48, an anti-HTT antibody (Fig. 1c). EM48-positive GFP signals were detected both in P1 and P4 of HD190QG transgenic mouse brains (TG), while no signals were detected in WT, indicating that nHTT inclusions were present in the P4 fraction. After the $2 \% \mathrm{SDS} / 10 \mathrm{mM}$ DTT and $70 \%$ FA treatment to P4, the solubilized fractions were considered to include the components of NIIs. Western blot was performed with the P1 and FA-treated fractions to confirm that the isolation of NIIs was successful. The SDS-soluble fraction was examined in order to compare it with the SDS-insoluble fractions that were later treated by FA (Fig. 1d). In the fractions obtained from the HD190QG brains, the ubiquitin antibody-positive signals were observed at the gel top of FA, while no signals were observed in the WT fractions. Since ubiquitin becomes covalently bonded to many types of pathological inclusions, such as neurofibrillary tangles in AD [28] and Lewy bodies in PD [29], the signals detected at the gel top in TG indicate that the fractions include ubiquitinated inclusions. To make sure that the nHTT inclusions from HD190QG were included in SDS-insoluble (FA-treated) fractions, the fractions were immunostained with an anti-GFP antibody and EM48. In TG, anti-GFP antibody-positive and EM48positive signals were detected not only at the gel top, but also inside the gel more strongly, indicating that solubilized monomers including human nHTT and EGFP with the size of around $75 \mathrm{kDa}$ were detected. Using this FAtreated fraction, the components of NIIs obtained from HD190QG including nHTT inclusions was investigated via LC-MS/MS analysis.

\section{Huntingtin and EGFP were identified in NIIs of HD190QG by LC-MS/MS}

As the FA-treated fraction is rich in NIIs directly obtained from HD190QG, we assumed that human huntingtin and EGFP would be identified by LC-MS/ MS. The trypsin digested FA-treated fractions of HD190QG and WT were subjected to LC-MS/MS. By comparing the relative scaled abundances between HD190QG and WT, 15 proteins including mouse huntingtin and EGFP were identified in NIIs of HD190QG (Additional file 1, Fig. 2a). Since human huntingtin was used for generating the HD190QG transgenic mice, we compared the sequences of mouse huntingtin and human huntingtin and found that both proteins shared 
a

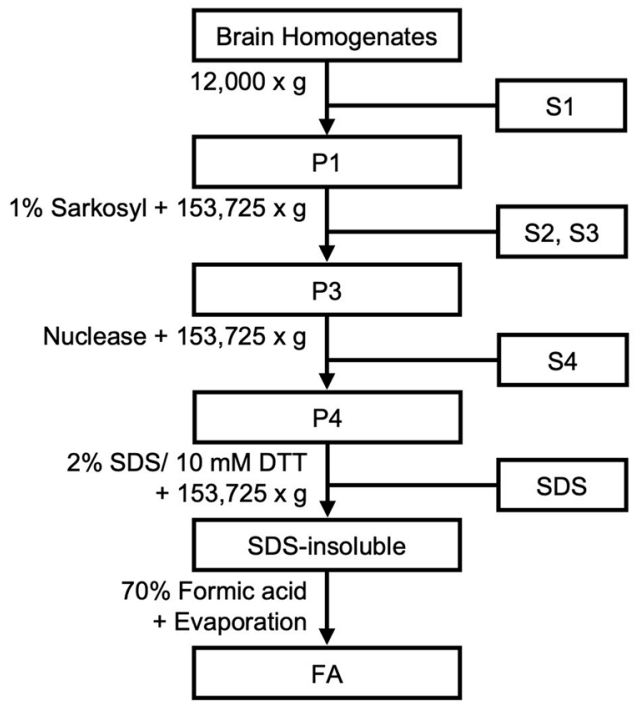

d

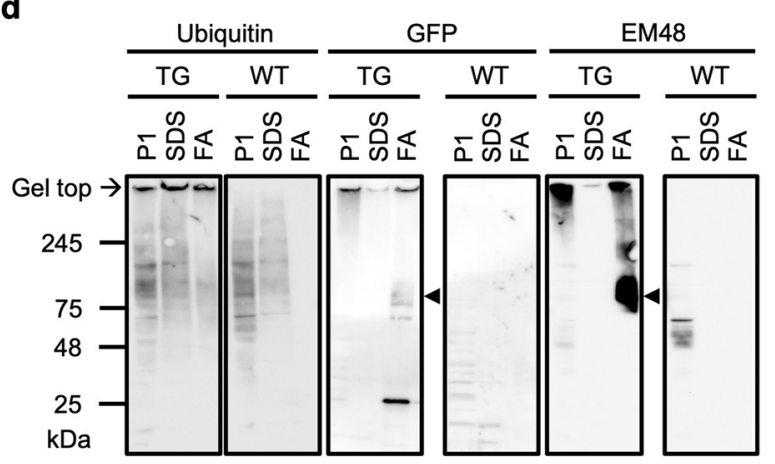

b

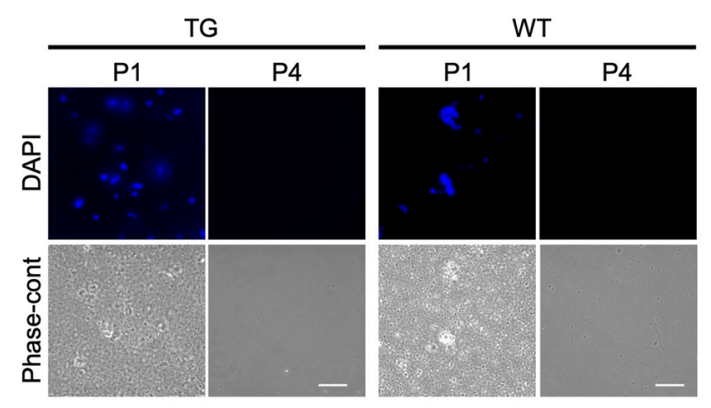

C
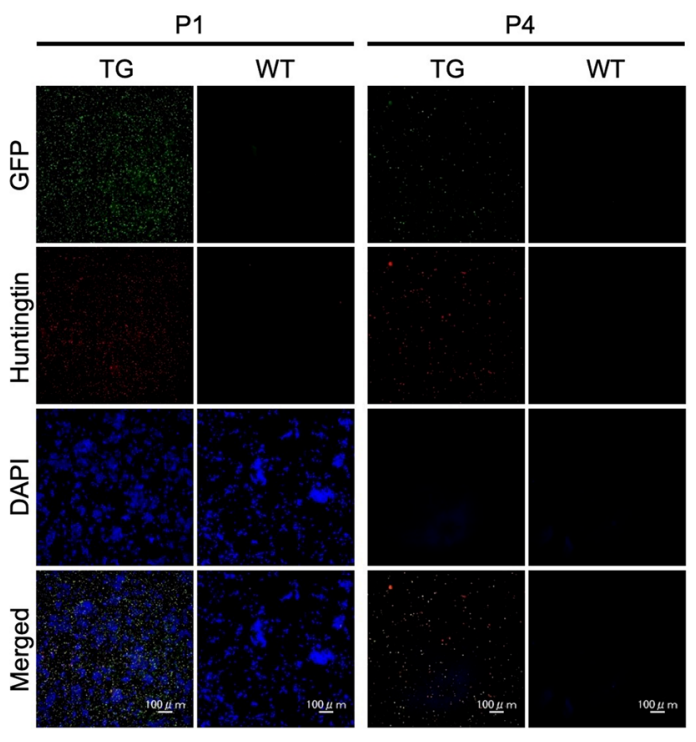

Fig. 1 The NII-rich fraction was isolated from HD190QG mouse brains. a HD190QG mouse brains were subjected to nuclei fractionation. After the 2\% SDS/10 mM DTT treatment, the SDS-insoluble fraction (SDS-insoluble) and the SDS-soluble fraction (SDS) were obtained. By treating the SDS-insoluble fraction with 70\% FA, NIls was obtained and used for further experiments (FA). b Phase-contrast microscopy of P1 and P4 fractions stained with DAPI. Scale bars $=50 \mu \mathrm{m}$. c IF staining of the P1 and P4 fractions stained with specific antibodies to GFP and huntingtin (EM48). Scale bars $=100 \mu \mathrm{m}$. $\mathbf{d}$ Western blotting of the P1, SDS and FA fractions stained with specific antibodies to ubiquitin, GFP and huntingtin (EM48). The broad bands indicated by arrowheads are NHTT-EGFP. TG refers to HD190QG transgenic mouse samples, and WT refers to wild type

the same sequence of the identified peptide. For EGFP, the identified sequences were found in the sequence of pEGFP-N1 vector, which was used for generating the HD190QG transgenic mice [26], indicating that the main components of nHTT inclusions were identified by LC-MS/MS (Fig. 2b). Next, we investigated the ubiquitination sites of nHTT in the NIIs. Previously, several ubiquitination sites of huntingtin were identified, and $K 6$ and $K 9$ were reported as the main sites for ubiquitination of the mutant huntingtin [30-32]. As ubiquitination occurs by forming an isopeptide bond between the C-terminal glycine of ubiquitin and a lysine of the target protein, we investigated whether there was a modification of glycine bound to lysine in the identified peptide of huntingtin. Until now, the modification of huntingtin inclusions isolated from animal brains analyzed by LC-MS/MS directly have not been reported, but we found that $\mathrm{K} 6$ was ubiquitinated (1xGG [K5] modification; Fig. 2a) using nHTT inclusions obtained from HD190QG mouse brains. Taken together, the LC-MS/MS analysis revealed that nHTT was the major component of NIIs of HD190QG and ubiquitinated at K6. However, LC-MS/MS analysis did not show the sequence with expanded polyglutamine. Therefore, we performed amino acid analysis using the SDS-insoluble fraction containing NIIs. 
a Huntingtin and EGFP identified by LC-MS/MS

\begin{tabular}{|c|c|c|c|c|c|}
\hline Description & Annotated Sequences & Positions & Modifications & Abs in TG & Abs in WT \\
\hline Huntingtin & ATLEKLMK & P42859 [2-9] & $\begin{array}{l}\text { 1xAcetyl [N-Term] } \\
\text { 1xOxidation [M7] } \\
\text { 1xGG [K5] }\end{array}$ & 200 & \\
\hline EGFP & $\begin{array}{l}\text { FSVSGEGEGDATYGK } \\
\text { SAMPEGYVQER } \\
\text { SAMPEGYVQER } \\
\text { FEGDTLVNR } \\
\text { TIFFKDDGNYK } \\
\text { AEVKFEGDTLVNR } \\
\text { LEYNYNSHNVYIMADK } \\
\text { LEYNYNSHNVYIMADK }\end{array}$ & $\begin{array}{l}\text { sp [28-42] } \\
\text { sp [87-97] } \\
\text { sp [87-97] } \\
\text { sp [115-123] } \\
\text { sp [98-108] } \\
\text { sp [111-123] } \\
\text { sp [142-157] } \\
\text { sp [142-157] }\end{array}$ & $\begin{array}{l}\text { 1xOxidation[M3] } \\
\text { 1xOxidation [13] }\end{array}$ & 199.5 & 0.5 \\
\hline
\end{tabular}

b The sequence of nHTT-EGFP

\begin{tabular}{|c|}
\hline 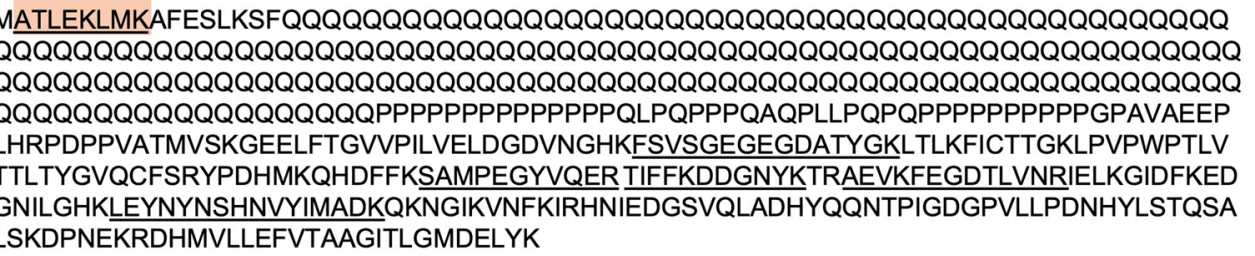 \\
\hline
\end{tabular}

Fig. 2 The peptides of huntingtin and EGFP were identified in the NIIs obtained from HD190QG mouse brains. a Huntingtin and EGFP were found only in the NIIs obtained from HD190QG transgenic mouse brains by LC-MS/MS. A modification 1XGG [K5] indicates that lysine 6 of huntingtin is ubiquitinated in insoluble nHTT inclusions. TG refers to HD190QG transgenic mouse samples, and WT refers to wild type. Abs refers to abundances. b The sequence of nHTT-EGFP with expanded polyglutamine (190Q) is shown, and the peptides identified by LC-MS/MS are underlined. The highlighted sequence was found both in mouse and human huntingtin

\section{Glutamine significantly increased in the NII-rich fraction of HD190QG brains}

Since the SDS-insoluble fraction was confirmed to contain NIIs earlier (Fig. 1d), and hydrolysis with $6 \mathrm{M} \mathrm{HCl}$ would be performed to cleave the peptide bonds in proteins during the amino acid analysis, we did not treat the fraction with $70 \%$ FA. The chromatograms of amino acid analysis of HD190QG and WT showed that glutamic acid increased significantly in HD190QG (Fig. 3a). Glutamine and glutamic acid were analyzed together due to deamidation of glutamine during the hydrolysis process, but the total protein quantification was not affected because they have nearly equivalent molecular weights (146.13 g/ mol for glutamine and $147.13 \mathrm{~g} / \mathrm{mol}$ for glutamic acid, respectively). Asparagine and aspartic acid were also analyzed together due to deamidation of asparagine during the hydrolysis process. To confirm that glutamic acid or glutamine in TG increased significantly compared to WT, we calculated the percentage of each amino acid in the SDS-insoluble fraction of the HD190QG mice and found that the percentage of glutamine or glutamic acid in TG increased by about 5.7 times compared to WT (Fig. 3b). We also calculated the percentage of amino acid numbers in the sequence of nHTT-EGFP with expanded polyglutamine (190Q) and normal repeat size (21Q) expressed in HD190QG. As a result, the calculated percentage of glutamic acid and glutamine in 190Q increased about 2.7 times compared to $21 \mathrm{Q}$ (Fig. S1). We also compared the results of real amino acid content (TG) with the calculated amino acid content of HD190QG (nHTT-EGFP) and found that glutamine or glutamic acid of the NII-rich fraction of HD190QG brains increased significantly and is compatible with the calculated amino acid content of HD190QG (Fig. 3c). Taken together, we directly analyzed the amino acid composition of the NII-rich fractions of HD190QG brains and assume that this method could be useful for the analysis of NIIs of diseased human brains, which may have proteins with compositionally biased regions (CBRs).

\section{The NII-rich fraction was obtained from the NIID brain}

The NIIs of the NIID brain and the control brains were isolated in the same way as the fractionation of NIIs from HD190QG mouse brains. The SDS-insoluble fractions were washed with $2 \%$ SDS/10 mM DTT solution after the first treatment to remove the remaining SDS-soluble proteins. Since the inclusions from the NIID brain used in this study are known to emit autofluorescence [2], we immunostained the P1 and P4 fractions with the anti-ubiquitin antibody to confirm that the autofluorescence is from the ubiquitinated inclusions (Fig. 4a). The autofluorescence observed in the NIID fractions 


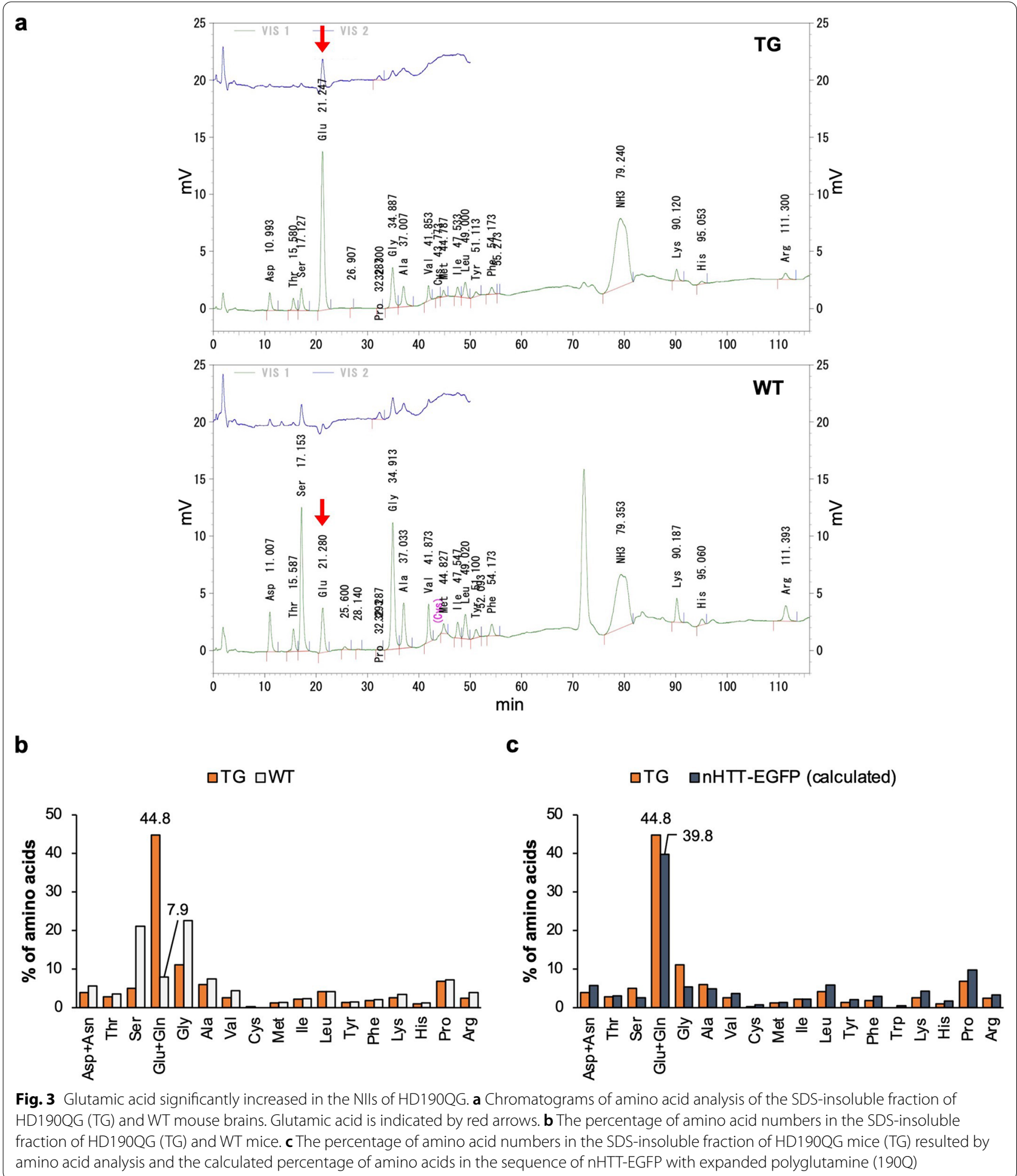

overlapped with the anti-ubiquitin antibody-positive signals, indicating that the autofluorescence came from the NIIs. In the control fractions, autofluorescence was also observed, but the signals did not overlap with anti-ubiquitin antibody-positive signals. The autofluorescence observed in the control brains may be from lipofuscin, also known as age pigment, which accumulates during normal senescence and cannot be digested by 
a

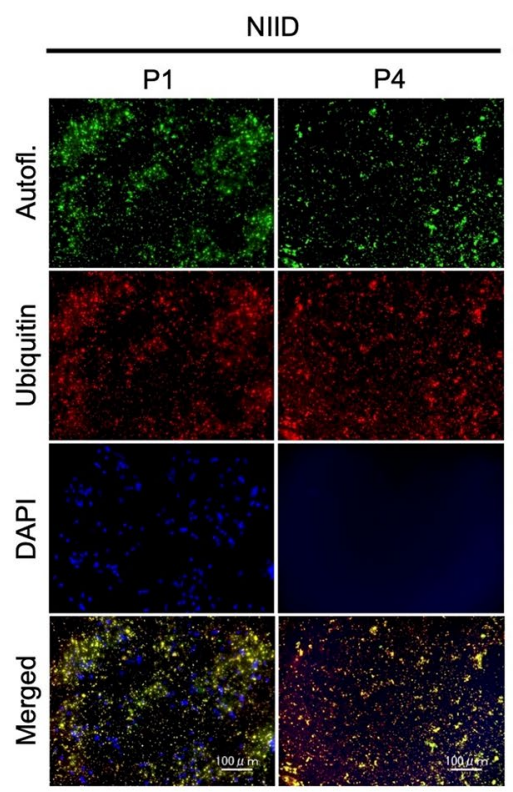

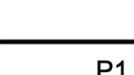

P1
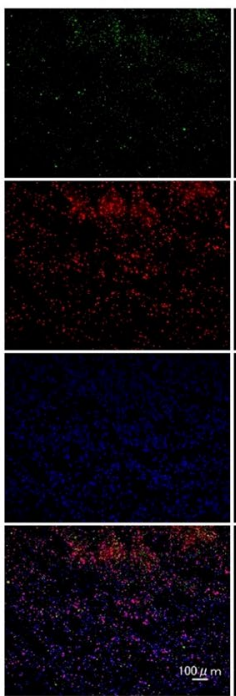

$100 \mu m$
Control 1

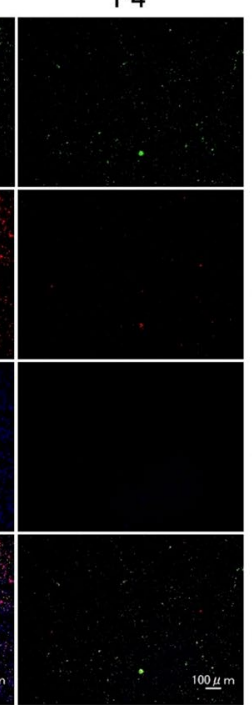

Control 2

P1

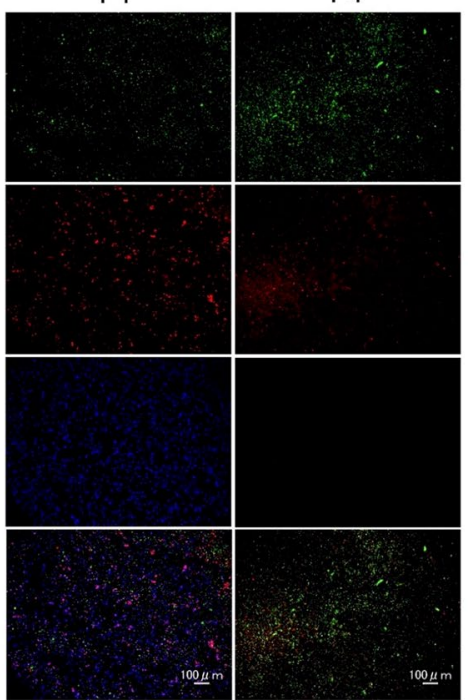

C b

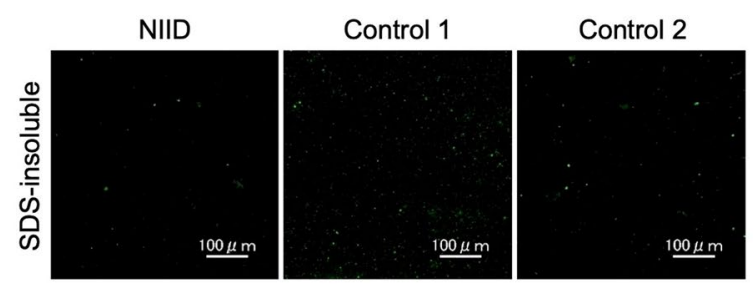

C

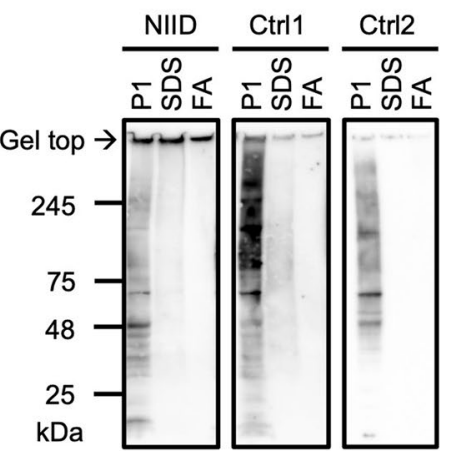

Fig. 4 The NII-rich fraction was isolated from NIID and the control brains. a P1 and P4 fractions of NIID and the control brains were immunostained with the anti-ubiquitin antibody. Green signals indicate the autofluorescence of NIIs, and red signals indicate ubiquitin positive molecules. DAPI signals are observed as blue. Overlapping autofluorescence and ubiquitin positive signals indicating Nils are observed as yellow in NIID. The autofluorescence observed in the control fractions could be lipofuscin, which does not overlap with ubiquitin positive signals. Scale bars $=100 \mu \mathrm{m}$. b Autofluorescence was observed in the SDS-insoluble fractions obtained from each brain sample. Scale bars $=100 \mu \mathrm{m}$. c P1, SDS-soluble (SDS) and FA-treated fraction (FA) were immunoblotted with the anti-ubiquitin antibody

the ubiquitin-proteasome system [33-35]. Autofluorescence was also observed in the SDS-insoluble fractions of all brain samples (Fig. 4b), which were later treated by $70 \%$ FA. Finally, immunoblot analysis with the anti-ubiquitin antibody revealed the gel-top staining, suggesting that NIIs were successfully isolated from the NIID brain (Fig. 4c). In order to investigate the composition of NIIs obtained from the NIID brain, the FA-treated fraction was subjected to LC-MS/MS.

\section{NIIs obtained from the NIID brain were rich in serine}

By performing LC-MS/MS with the trypsin-digested FA-treated fractions of the NIID and control brains, we observed 19 proteins that were specifically identified in NIIs from the NIID brain (Additional file 2, Table 1). We postulated that among the 19 proteins, including known nuclear proteins, any proteins that are related to either the formation of NIIs or the disease pathogenesis could be found. For amino acid analysis, the SDS-insoluble fractions of each brain sample were hydrolyzed by $4 \mathrm{~N}$ Methanesulfonic acid instead of $6 \mathrm{M} \mathrm{HCl}$ to prevent hydrolyzing tryptophan. In the NIID sample, we detected about 3.8 times more serine than in Control 1 and about 2.3 times more than in Control 2 samples, while all other amino acids were detected lesser amounts than in the controls (Fig. 5a, b). To figure out which protein in 
Table 1 The proteins in NIIs specifically identified in the NIID brains

\begin{tabular}{ll}
\hline Protein description & Accession \\
\hline Small ubiquitin-related modifier 3 (SUMO3) & P55854 \\
Thioredoxin (TXN) & P10599 \\
Ubiquitin-40S ribosomal protein S27a (RPS27A) & P62979 \\
Histone H2B type 1-A (H2BC1) & Q96A08 \\
Claudin-11 (CLDN11) & O75508 \\
Sodium/hydrogen exchanger 1 (SLC9A1) & P19634 \\
Hemogen (HEMGN) & Q9BXL5 \\
Hornerin (HRNR) & Q86YZ3 \\
Syntaxin-binding protein 5-like (STXBP5L) & Q9Y2K9 \\
Inter-alpha-trypsin inhibitor heavy chain (ITIH5) & Q86UX2 \\
Leucine-rich repeat and IQ domain-Containing protein 1 (LRRIQ1) & Q96JM4 \\
Neuroblastoma breakpoint family member 19 (NBPF19) & A0A087WUL8 \\
Actin, aortic Smooth muscle (ACTA2) & P62736 \\
Potassium-transporting ATPase alpha chain 1 (ATP4A) & P20648 \\
Guanine nucleotide-binding protein G(S) subunit alpha isoforms XLas (GNAS) & Q5JWF2 \\
Tubulin alpha-1B chain (TUBA1B) & P68363 \\
Hemoglobin subunit beta (HBB) & P68871 \\
Decorin (DCN) & P07585 \\
Creatine kinase U-type, mitochondrial (CKMT1A) & P12532 \\
\hline
\end{tabular}

NIID was rich in serine, we calculated the percentage of amino acid numbers in the sequences of all the identified proteins and found that hornerin (HRNR) was the most serine-rich protein (Fig. 5c). We also confirmed that the pattern of amino acid contents in NIIs and hornerin are similar (Fig. 5d), indicating that hornerin might be one of the major components of the NIIs in NIID.

\section{Hornerin is the major component of NIIs in NIID}

To confirm that hornerin is the major component of the NIIs, we performed Western blot using the P1 and P4 fractions of NIID. Anti-hornerin antibody-positive bands with the sizes of $100 \mathrm{kDa}$ and $245 \mathrm{kDa}$ were detected in P4 fraction (Fig. 6a). As the amount of protein seemed to be the same in each fraction of NIID, Control 1 and Control 2 (Fig. 6b), we hypothesized that the protein bands detected by Western blot would contain fragments of hornerin. To obtain and identify the peptides of interest stained by $\mathrm{CBB}$, we performed in-gel tryptic digestion and LC-MS/MS and found that all the anti-hornerin antibody-positive bands contained the peptides of hornerin (Additional file 2, Additional file 4: Table S1 and Fig. S2). These results suggest that hornerin is one of the major components in the NIIs of NIID.

\section{A specific distribution of hornerin in the NIID brain was observed by MALDI-IMS}

Since LC-MS/MS revealed that hornerin was specifically identified in NIIs of NIID, we investigated the distribution of hornerin using an integrated analysis of MALDI-IMS and shotgun proteomics (LC-TIMS-MS/ MS). MALDI-IMS is a technique for investigating the distribution of proteins and small molecules within biological systems, through the direct in situ analysis of tissue sections $[22,36]$. The brain sections of NIID, AD and a control were used for MALDI-IMS and analyzed computationally. For LC-TIMS-MS/MS, we used 3 Gy matter samples and 2 white matter samples of NIID and other diseased brains, such as multiple system atrophy, progressive supranuclear palsy, $\mathrm{AD}$ and $\mathrm{AD} /$ cerebral amyloid angiopathy, as well as a control brain. The result of the integrated analyses of MALDI-IMS and LC-TIMS-MS/ MS showed that the hornerin peptides were identified both in gray matter samples and white matter samples (Table S1 and Fig. S2), and a specific distribution in NIID was observed at $1,584 \mathrm{~m} / \mathrm{z}$ (Fig. 7). This result corresponds to the LC-MS/MS result using the FA-treated fraction of NIIs (Additional file 2). In addition, more peptides were identified in the white matter samples compared to the gray matter samples.

\section{The localization of hornerin on NIls was observed in the NIID brain by immunofluorescence}

In order to study the distribution of hornerin in the NIID brain, IF staining was performed on NIID sections, using a custom antibody termed anti-HRNR (HP), designed to detect human hornerin ${ }_{968-1349}$. Anti-ubiquitin antibody was used for a positive control, and immunostaining 


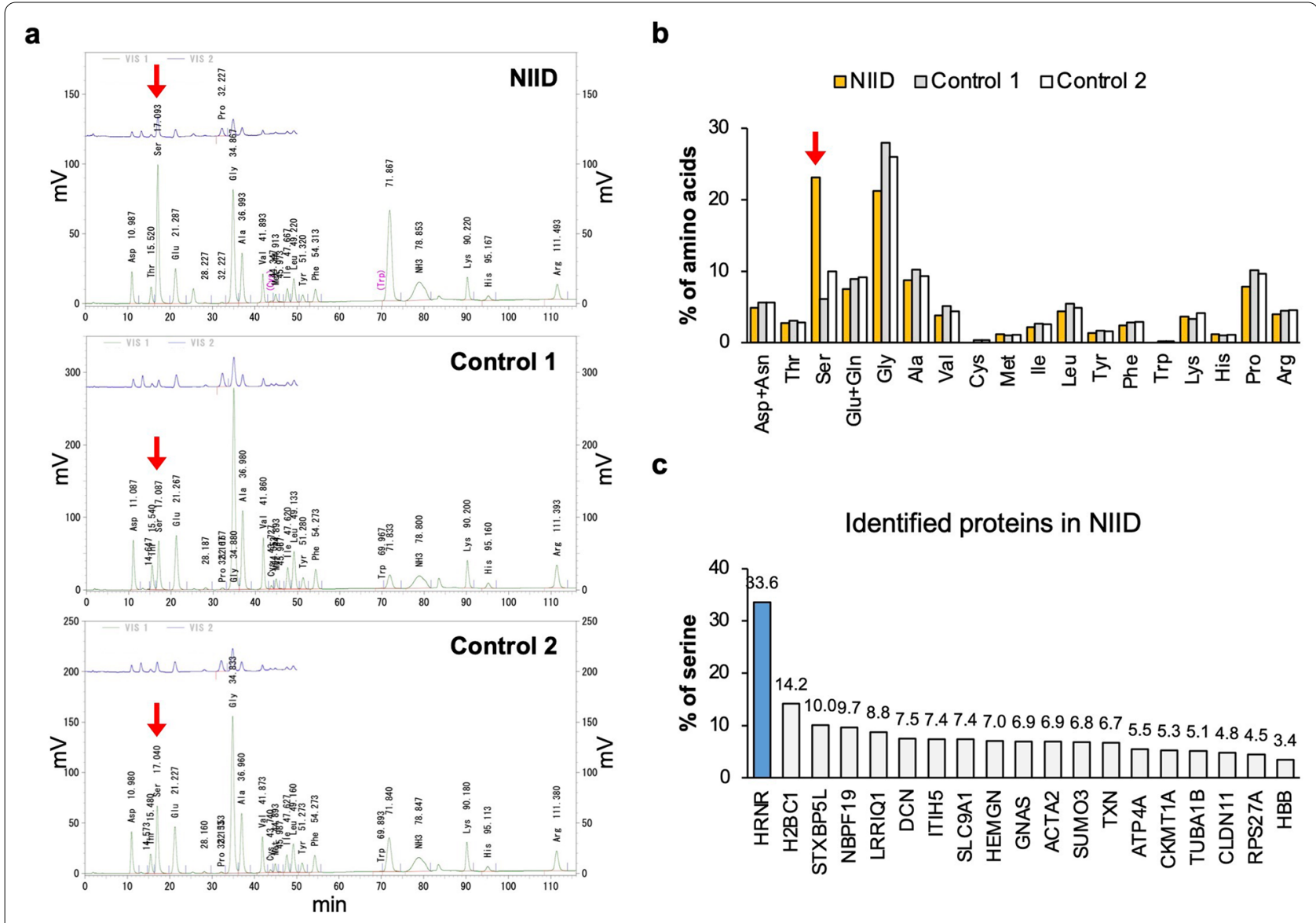

d

口NIID aHornerin

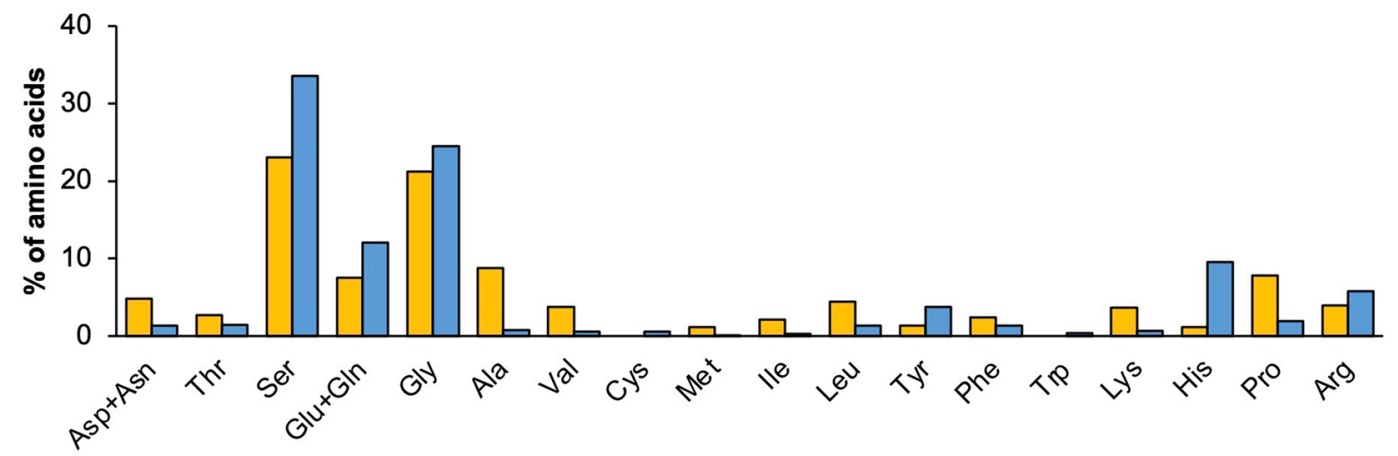

Fig. 5 Serine significantly increased in NIIs obtained from the NIID brain. a Chromatograms of amino acid analysis using the SDS-insoluble fraction of NIID and the control brains. Serine is indicated by red arrows. $\mathbf{b}$ The calculated percentage of amino acid numbers in Nlls obtained from each brain. Serine is indicated by a red arrow. c The percentage of serine in the proteins identified in NIID. $\mathbf{d}$ The comparison between the percentage of amino acids of NIIs obtained from the NIID brain and the percentage of amino acids of hornerin protein

without any primary antibodies was performed as a negative control. All the NIID sections showed autofluorescence, and we found that anti-HRNR (HP) antibodypositive signals co-localized with the autofluorescent inclusions (Fig. 8).

\section{The Ser1008Thr variant in the HRNR gene was found} in the NIID

We next analyzed whole-exome sequencing and longread sequencing data of genomic DNA extracted from the brain of the NIID patient in order to identify 

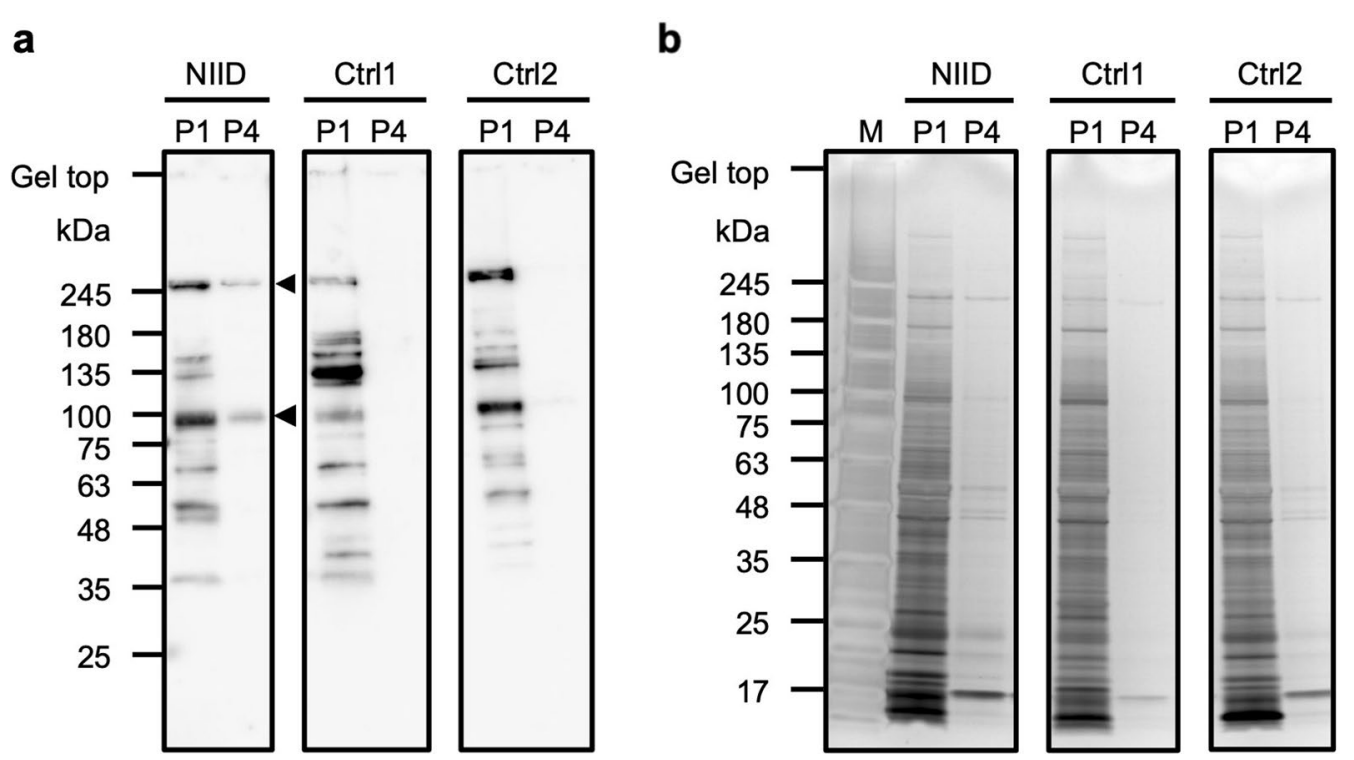

Fig. 6 Hornerin was detected specifically in the NIID fractions. a Immunoblotting of hornerin with the P1 and P4 fractions. Arrowheads indicate anti-hornerin antibody-positive bands ( $245 \mathrm{kDa}$ and $100 \mathrm{kDa}$ ). b Silver staining of the P1 and P4 fractions obtained from each brain sample

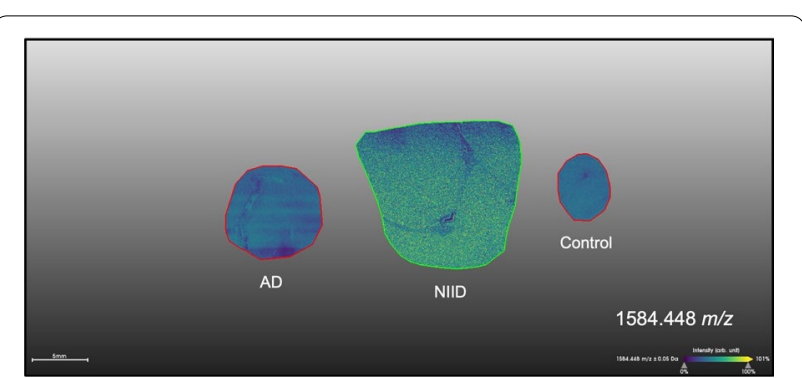

Fig. 7 A specific distribution of the Hornerin peptide was detected by MALDI-IMS. MALDI-IMS was performed with brain sections of NIID, AD and a control. The distribution of the peptide at 1,584 m/z detected by LC-MS earlier was observed

pathogenic variants. In this NIID case, the pathogenic GGC expansion was not identified in the NOTCH2NLC gene and other genes by long-read sequencing. The sequence analysis revealed a nonsynonymous variant NM_001009931.3:c.3023G > C, p. (Ser1008Thr) within exon 3 of the human $H R N R$ gene with an amino acid change from serine to threonine at position 1008 (Fig. 9a). To confirm that this variant is heterozygous, DNA sequencing was performed with the PCR products derived from NIID and the control brains, as well as Hela and HEK293T cells. The primers were designed to amplify serine or threonine at position 1008 (Fig. 9b) and checked by PCR to ensure the primer efficiencies and also that they generated single bands of the predicted size (Fig. 9c). The PCR products were sequenced, and the G3023C variant was found heterozygously in NIID (Fig. 9d).

\section{Discussion}

Until now, it has been difficult to analyze the protein components of NIIs directly due to the protein's structural features and insolubility. In fact, polyglutamine was not identified by LC-MS/MS in insoluble fractions of HD model mouse brains (Additional file 1). This might be because protein cores are hard to solubilize, and thus cannot be ionized for LC-MS/MS. Therefore, we combined LC-MS/MS with amino acid analysis in order to search for candidate pathogenic proteins of NIID [2]. Because amino acid analysis showed a high content of serine in the NII-rich fraction, and hornerin was found to be serine-rich, we assumed that hornerin could be a main component of the NIIs in our patient. Based on the unique distribution of hornerin in NIID and the antihornerin antibody-positive signals in the NIIs, as shown by MALDI-IMS and IF staining respectively, we suggest that hornerin is the main component of the NIIs being involved in the pathogenic cascade of the disease.

Human hornerin is a $245 \mathrm{kDa}$ protein which shares structural features with S100 fused-type proteins, particularly with profilaggrin. In mice, hornerin was found to be expressed in cornifying stratified epithelium, including the epidermis, tongue, esophagus, and forestomach. In the epidermis, hornerin co-localized with profilaggrin in keratohyalin granules, indicating 


\section{a}

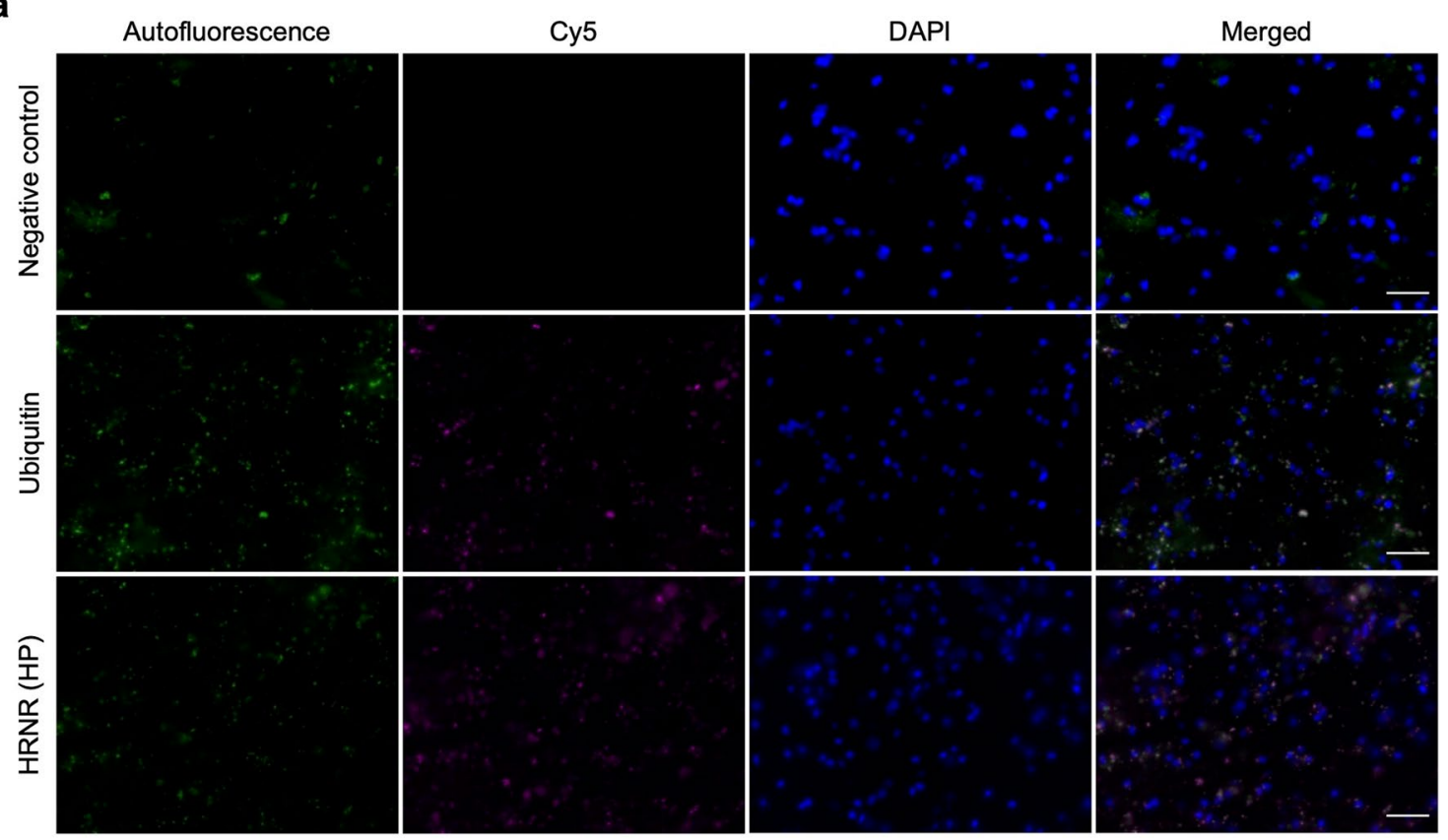

b
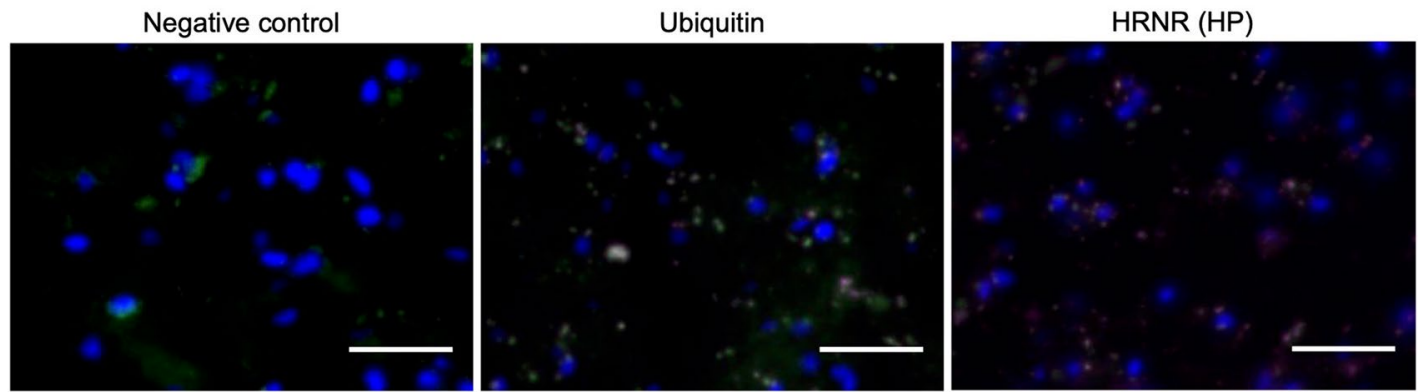

Fig. 8 Hornerin was detected in the NIID brain sections by IF staining. a IF staining of the NIID brain sections with the anti-ubiquitin and anti-HRNR (HP) antibodies. Autofluorescent signals are shown in green, and the antibody-positive signals are shown in pink (Cy5). The cells are stained with DAPI (blue). Scale bars $=100 \mu \mathrm{m}$. b Enlarged images of the merged images in $\mathbf{a}$ Scale bars $=100 \mu \mathrm{m}$

that hornerin plays roles similar to those of profilaggrin in the cornifying epithelium [37, 38]. The expression of hornerin was also observed in mouse neurons (Allen mouse brain atlas, https://mouse.brain-map.org/ gene/show/44565). In humans, hornerin was detected in regenerating skin after wounding and in psoriatic skin [37]. Hornerin was also expressed abundantly in healthy human skin with unusual biochemical characteristics including forming and auto-degrading properties of aggregates [39]. The roles of hornerin in tumor progression or vascularity in several cancers including breast cancer [40, 41], hepatocellular carcinoma [42] and pancreatic ductal carcinoma [43] have been investigated. Although the expression of hornerin has been observed in many tissues, its expression in human brain sections has not been reported, and little is known about the roles of hornerin in neurodegenerative diseases.

Hornerin is an IDP with LCRs or CBRs, which contains $95 \%$ tandem quasi-repeating glycine- and serinerich domains. Unlike globular proteins, IDPs contain a low quantity of hydrophobic amino acids, stabilizing the protein structures, but are rich in polar and charged amino acids, interacting favorably with water $[44,45]$. This low sequence complexity of IDPs may affect protein misfolding and aggregation in neurodegenerative diseases such as AD and PD. In fact, many disease-related IDPs, including a-syn and tau, are found to contain LCRs or CBRs in their sequences. It is challenging to identify the components of protein aggregates by LC-MS/MS, which we tried using to identify polyglutamine in NIIs of HD190QG model mice. However, it could not identify 


\section{a In silico analysis of hornerin variants}

\begin{tabular}{|l|l|l|l|l|l|l|l|l|}
\hline \multicolumn{2}{|c|}{ Variants } & \multicolumn{2}{c|}{ SIFT } & \multicolumn{2}{c|}{ PolyPhen-2 } & \multicolumn{2}{c|}{ Mutation taster } & gnomAD \\
\hline Gene & $\begin{array}{l}\text { Nucleotide/ } \\
\text { Protein }\end{array}$ & Score & Prediction & Score & $\begin{array}{l}\text { Prediction } \\
\text { (HumVar) }\end{array}$ & Value & Prediction & $\begin{array}{l}\text { Allele } \\
\text { frequency }\end{array}$ \\
\hline $\begin{array}{l}\text { HRNR } \\
\text { NM_001009931.3 }\end{array}$ & $\begin{array}{l}\text { c.3023G>C/ } \\
\text { p. (Ser1008Thr) }\end{array}$ & 0.53 & Tolerated & 0.528 & $\begin{array}{l}\text { Possibly } \\
\text { damaging }\end{array}$ & 0.999 & polymorphism & 0.001806 \\
\hline
\end{tabular}

b

TCTAGGAGCGAACAACATGGATCTAGCTCAGGTTCGTCTTCCAGCTATGGTCAGCATGGGTCTGGC

$S$ R $S$ E $Q$ Q TCCCGTCAGTCTTTGGGCCACGGCCAACATGGGTCTGGATCTGGCCAGTCTCCTAGCCCTAGCCGT $\begin{array}{llllllllllllllllllllllllll}S & R & Q & S & L & G & H & G & Q & H & G & S & G & S & G & Q & S & P & \text { (S) } & P & S & R\end{array}$ GGCCGACATGGGTCTGGTTCCGGGCAGTCTTCCAGCTATGGCCCATATAGGTCTGGCTCAGGGTGG

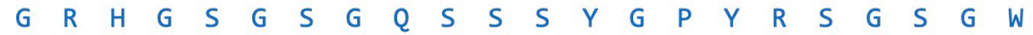
TCTTCAAGCCGTGGCCCATATGAGTCTGGCTCCGGTCACTCTTCTGGCTTAGGTCACCGAGAGTCT

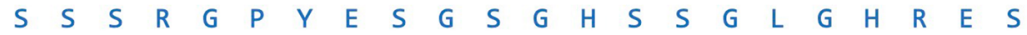
CGCTCAGGACAGTCCTCTGGCTACGGTCAACATGGATCTAGCTCAGGTCATTCCTCTACCCATGGG

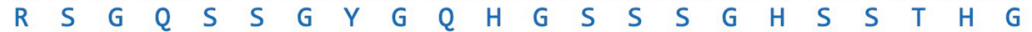
CAACACGGTTCTACATCAGGACAGTCATCGAGCTGTGGCCAACATGGAGCTAGCTCAGGTCAGTCT Q TCCAGCCACGGTCAGCATGGCTCTGGCTCAAGTCAGTCTTCTGGCTAT

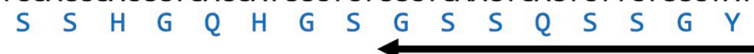

C

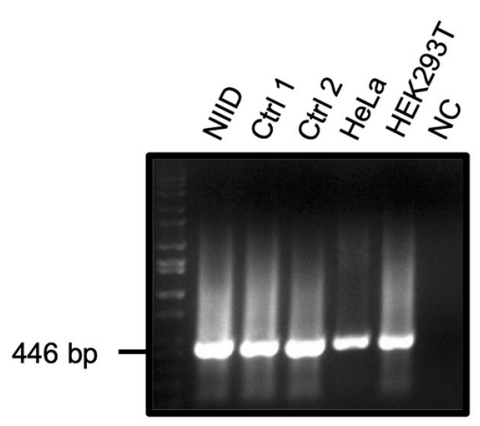

d
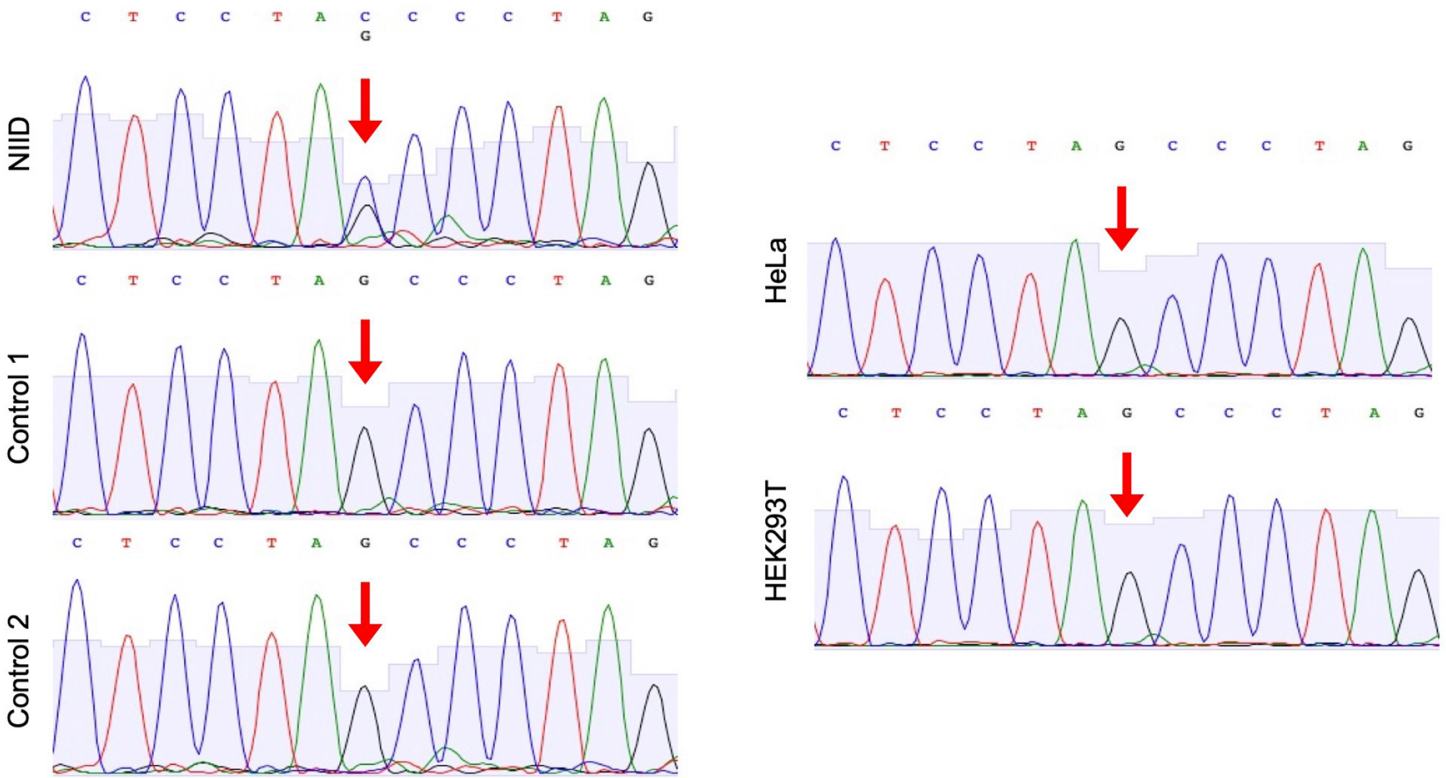

Fig. 9 The analysis of hornerin variants. a A nonsynonymous variant, c.3023G > C/p. (Ser1008Thr), was found in the gene HRNR by the whole-exome sequencing. SIFT: The amino acid substitution is predicted. Scores range from 0 to 1 . Damaging if the score is $\leq 0.05$ and tolerated if the score is $>0.05$ (https://sift.bii.a-star.edu.sg/www/SIFT_seq_submit2.html). PolyPhen-2: scores were evaluated from 0.000 (most probably benign) to 0.999 (most probably damaging). Mutation Taster: a value close to 1 indicates a high security of the prediction, and the alterations are classified as disease causing or polymorphisms. gnomAD: Genome Aggregation Database (http://gnomad.broadinstitute.org/). b DNA sequence of the PCR product used for variant detection. Oligonucleotide primers are shown by arrows. Amino acid translation is shown below the DNA sequence. The circled base represents the $\mathrm{G} 3023 \mathrm{C}$ change in the mutant allele. The resulting amino acid Ser1008Thr change is represented by the circled amino acid. $\mathbf{c}$ PCR was performed with genomic DNAs of NIID, Control 1, Control 2 brains as well as HeLa and HEK293T cells. NC refers to negative control. $\mathbf{d}$ The G3023C variant in NIID was confirmed by DNA sequencing. The variant site is shown by red arrows 
expanded polyglutamine of huntingtin, which has low sequence complexity. Therefore, we performed amino acid analysis and successfully confirmed that glutamine increased significantly in NIIs of HD190QG (Fig. 3). By combining LC-MS/MS and amino acid analysis with additional bioinformatic analyses, we found a significantly increased serine content in the NII-rich fraction obtained from the NIID brain, later identified as hornerin deposits. Thus, it is important to analyze either the protein aggregates or the NII-rich fraction of those diseases at amino acid level. In addition, since the first discovery of RAN translation in SCA8 and myotonic dystrophy type 1, RAN translated products have been suggested in a growing number of diseases including fragile $\mathrm{X}$ tremor ataxia syndrome, HD and SCA31 [46]. RAN translation could produce the proteins with CBRs. Our methods should be used to investigate protein aggregates in those diseases.

Since hornerin was found in NIIs, we investigated whether this protein has nuclear localization signals (NLSs) via several computational NLS prediction tools: cNLS Mapper [47], NLStradamus [48] and seqNLS [49]. However, no NLS was predicted in the sequence of hornerin, and how hornerin could be imported to the nucleus without NLS remains unclear. A previous study reported that $\mathrm{N}$-terminal spacer domain peptides of profilaggrin, which shares features with hornerin, are transported to the nucleus [50]. There are also some proteins that do not have NLS but can be transported to the nucleus in their NLS-independent manner [51]. Hornerin might be one of these proteins that can be transported to the nucleus NLS-independently. Further studies are necessary to investigate the nuclear entry mechanism of hornerin.

The disease-related IDPs also undergo post-translational modifications (PTMs) such as phosphorylation or ubiquitination, which may enhance their aggregation property $[52,53]$. In our LC-MS/MS analysis results, ubiquitination of hornerin was not identified. This might be because ubiquitinated fragments were not included in the identified peptides. However, carbamylation at $\mathrm{N}$-termini was found as a PTM that hornerin might undergo (Additional file 2). Since carbamylation of lysine residues and protein $\mathrm{N}$-termini, which is a hallmark of aging, can be artificially introduced during sample preparation with urea [54], the direct effect of carbamylation on the properties of hornerin remains unclear. Although we could not detect other modifications in our study, hornerin fragments were identified in the Western blot. This fragmentation could enhance the aggregation property of hornerin.

In this NIID case, the pathogenic variants of known NIID genes NOTCH2NLC and CAG repeats were not identified. Our protein chemical analysis clearly showed hornerin is the major component of NIIs of this NIID. However, it is still possible that an unidentified gene with repeat expansion producing polyserine is the pathogenic gene of this NIID, and hornerin is recruited to the polyserine inclusion. Further revised long-read sequencing to detect repeat expansion expressing polyserine is necessary. Although we found LRRK2:NM_198578:exon38:c. T5606C:p.M1869T [55], this variant is responsible for adult-onset PD, therefore, it is unrelated to this NIID. A variant (G3023C) within the human HRNR gene with an amino acid change (Ser1008Thr) was found via whole-exome sequencing of this NIID (Additional file 3). However, using gnomAD browser [56], we found that the allele frequency of this variant is 0.001806 (Fig. 9a). This means that this variant in HRNR occurs 1 in 300 Europeans, while other known pathogenic gene variants such as the Gly2019Ser variant of LRRK2 in PD (1 in 2,400 Europeans) or the Arg521Cys variant of FUS in amyotrophic lateral sclerosis (1 in 25,000 Europeans) are much less frequent. Most of the heterozygous variants, which cause serious symptoms from early childhood, are de novo. However, in terms of frequency, it is hard to think that this Ser1008Thr variant is de novo. Since the in silico prediction also revealed that the variant is nonpathogenic (Fig. 9a), this variant itself is unlikely to be responsible for NIID. Although more analyses are certainly needed to determine the genetic role of hornerin variants, a hornerin cascade should be recognized as a pathology of this disease. In this regard, the variant analysis of genes related to hornerin binding proteins should be investigated.

\section{Supplementary Information}

The online version contains supplementary material available at https://doi. org/10.1186/s40478-022-01333-8.

Additional file 1: LC-MS/MS result of HD190QG mouse brains.

Additional file 2: LC-MS/MS result of NIID and control brains.

Additional file 3: Whole exome sequencing data.

Additional file 4.: Table S1. The identified hornerin peptides by LC-MS/ MS and LC-TIMS-MS/MS. Figure S1. The calculated percentage of amino acids in the sequence of nHTT-EGFP. Figure S2. The hornerin peptides identified by LC-MS/MS and LC-TIMS-MS/MS.

\section{Acknowledgements}

We thank Kaori Otsuki and Hiromasa Morishita at RIKEN BMA Mass Spectrometry Service for performing LC-MS/MS and amino acid analysis. This work was supported by AMED to SM (19dm0107103) and NM (JP21ek0109486, JP21ek0109549, JP21 cm0106503 and JP21ek0109493) and the Ministry of Education, Culture, Sports, Science and Technology (MEXT) of Japan to NN (17H01564), TY (17KT0131), AF (JP20K17936) and SM (16H06277).

\section{Authors' contributions}

HP designed and performed experiments with advice of TY. AF, HD and NM performed whole exome sequencing. YT and TN performed MALDI-IMS and 
LC-TIMS-MS/MS with advice of MI. SM performed the pathological analysis. TS performed LC-MS/MS analysis. NN and MJH started this study. NN supervised the whole project. HP and NN wrote the manuscript. All authors read and approved the final manuscript.

\section{Declarations}

\section{Competing interests}

The authors declare that they have no competing interests.

\section{Author details}

${ }^{1}$ Laboratory of Structural Neuropathology, Doshisha University Graduate School of Brain Science, 1-3 Miyakodanitatara, Kyotanabe-shi, Kyoto 610-0394, Japan. ${ }^{2}$ Department of Neuroscience of Disease, Brain Research Institute, Niigata University, Niigata, Japan. ${ }^{3}$ Department of Life and Medical Systems, Doshisha University, Kyoto, Japan. ${ }^{4}$ Department of Human Genetics, Yokohama City University Graduate School of Medicine, Yokohama, Japan. ${ }^{5}$ Department of Neurology and Stroke Medicine, Yokohama City University Graduate School of Medicine, Yokohama, Japan. ${ }^{6}$ Bruker Japan K.K., Yokohama, Japan. ${ }^{7}$ The Brain Bank for Aging Research, Tokyo Metropolitan Geriatric Hospital and Institute of Gerontology, Tokyo, Japan. ${ }^{8}$ Molecular Mechanisms of Brain Development, RIKEN Center for Brain Science, Saitama, Japan. ${ }^{9}$ Department of Pathology, Faculty of Medicine, University of Helsinki, Helsinki, Finland. ${ }^{10}$ Laboratory for Structural Neuropathology, RIKEN Brain Science Institute, Saitama, Japan.

\section{Received: 21 December 2021 Accepted: 16 February 2022} Published online: 04 March 2022

\section{References}

1. Lindenberg R, Rubinstein $\sqcup$, Herman MM, Haydon GB (1968) A light and electron microscopy study of an unusual widespread nuclear inclusion body disease. A possible residuum of an old herpesvirus infection. Acta Neuropathol 10(1):54-73

2. Haltia M, Somer H, Palo J, Johnson WG (1984) Neuronal intranuclear inclusion disease in identical twins. Ann Neurol 15(4):316-321

3. Weidenheim KM, Dickson DW (1995) Intranuclear inclusion bodies in an elderly demented woman: a form of intranuclear inclusion body disease. Clin Neuropathol 14(2):93-99

4. Takahashi-Fujigasaki J (2003) Neuronal intranuclear hyaline inclusion disease. Neuropathology 23(4):351-359

5. Sone J, Mori K, Inagaki T, Katsumata R, Takagi S, Yokoi S et al (2016) Clinicopathological features of adult-onset neuronal intranuclear inclusion disease. Brain 139(Pt 12):3170-3186

6. Chen Z, Yan Yau W, Jaunmuktane Z, Tucci A, Sivakumar P, Gagliano Taliun SA et al (2020) Neuronal intranuclear inclusion disease is genetically heterogeneous. Ann Clin Transl Neurol 7(9):1716-1725

7. Takahashi-Fujigasaki J, Arai K, Funata N, Fujigasaki H (2006) SUMOylation substrates in neuronal intranuclear inclusion disease. Neuropathol Appl Neurobiol 32(1):92-100

8. Davies SW, Beardsall K, Turmaine M, DiFiglia M, Aronin N, Bates GP (1998) Are neuronal intranuclear inclusions the common neuropathology of triplet-repeat disorders with polyglutamine-repeat expansions? Lancet 351(9096):131-133

9. Lieberman AP, Shakkottai VG, Albin RL (2019) Polyglutamine repeats in neurodegenerative diseases. Annu Rev Pathol 14:1-27

10. Wright PE, Dyson HJ (2015) Intrinsically disordered proteins in cellular signalling and regulation. Nat Rev Mol Cell Biol 16(1):18-29

11. Mitrea DM, Kriwacki RW (2016) Phase separation in biology; functional organization of a higher order. Cell Commun Signal 14:1

12. Zu T, Gibbens B, Doty NS, Gomes-Pereira M, Huguet A, Stone MD et al (2011) Non-ATG-initiated translation directed by microsatellite expansions. Proc Natl Acad Sci U S A 108(1):260-265

13. Sone J, Tanaka F, Koike H, Inukai A, Katsuno M, Yoshida M et al (2011) Skin biopsy is useful for the antemortem diagnosis of neuronal intranuclear inclusion disease. Neurology 76(16):1372-1376

14. Sone J, Mitsuhashi S, Fujita A, Mizuguchi T, Hamanaka K, Mori Ket al (2019) Long-read sequencing identifies GGC repeat expansions in
NOTCH2NLC associated with neuronal intranuclear inclusion disease. Nat Genet 51(8):1215-1221

15. Ishiura H, Shibata S, Yoshimura J, Suzuki Y, Qu W, Doi K et al (2019) Noncoding CGG repeat expansions in neuronal intranuclear inclusion disease, oculopharyngodistal myopathy and an overlapping disease. Nat Genet 51(8):1222-1232

16. Yu J, Deng J, Guo X, Shan J, Luan X, Cao L et al (2021) The GGC repeat expansion in NOTCH2NLC is associated with oculopharyngodistal myopathy type 3. Brain 144(6):1819-1832

17. Boivin M, Deng J, Pfister V, Grandgirard E, Oulad-Abdelghani M, Morlet B et al (2021) Translation of GGC repeat expansions into a toxic polyglycine protein in NIID defines a novel class of human genetic disorders: The polyG diseases. Neuron 109(11):1825-35.e5

18. Jedlickova I, Pristoupilova A, Hulkova H, Vrbacka A, Stranecky V, Hruba E et al (2020) NOTCH2NLC CGG repeats are not expanded and skin biopsy was negative in an infantile patient with neuronal intranuclear inclusion disease. J Neuropathol Exp Neurol 79(10):1065-1071

19. Kotliarova S, Jana NR, Sakamoto N, Kurosawa M, Miyazaki H, Nekooki M et al (2005) Decreased expression of hypothalamic neuropeptides in Huntington disease transgenic mice with expanded polyglutamine-EGFP fluorescent aggregates. J Neurochem 93(3):641-653

20. Wisniewski JR, Zougman A, Nagaraj N, Mann M (2009) Universal sample preparation method for proteome analysis. Nat Methods 6(5):359-362

21. Shalit T, Elinger D, Savidor A, Gabashvili A, Levin Y (2015) MS1-based label-free proteomics using a quadrupole orbitrap mass spectrometer. J Proteome Res 14(4):1979-1986

22. Ikegawa M, Nirasawa T, Kakuda N, Miyasaka T, Kuzuhara Y, Murayama S et al (2019) Visualization of amyloid beta deposits in the human brain with matrix-assisted laser desorption/ionization imaging mass spectrometry. J Vis Exp 145:e57645

23. Doi H, Koyano S, Miyatake S, Nakajima S, Nakazawa Y, Kunii M et al (2018) Cerebellar ataxia-dominant phenotype in patients with ERCC4 mutations. J Hum Genet 63(4):417-423

24. Frith MC, Khan S (2018) A survey of localized sequence rearrangements in human DNA. Nucleic Acids Res 46(4):1661-1673

25. Mitsuhashi S, Frith MC, Mizuguchi T, Miyatake S, Toyota T, Adachi H et al (2019) Tandem-genotypes: robust detection of tandem repeat expansions from long DNA reads. Genome Biol 20(1):58

26. Oyama F, Miyazaki H, Sakamoto N, Becquet C, Machida Y, Kaneko Ket al (2006) Sodium channel beta4 subunit: down-regulation and possible involvement in neuritic degeneration in Huntington's disease transgenic mice. J Neurochem 98(2):518-529

27. Kino Y, Washizu C, Kurosawa M, Yamada M, Doi H, Takumi T et al (2016) FUS/TLS acts as an aggregation-dependent modifier of polyglutamine disease model mice. Sci Rep 6:35236

28. Morishima-Kawashima M, Hasegawa M, Takio K, Suzuki M, Titani K, Ihara $Y$ (1993) Ubiquitin is conjugated with amino-terminally processed tau in paired helical filaments. Neuron 10(6):1151-1160

29. Wakabayashi K, Tanji K, Mori F, Takahashi H (2007) The Lewy body in Parkinson's disease: molecules implicated in the formation and degradation of alpha-synuclein aggregates. Neuropathology 27(5):494-506

30. Steffan JS, Agrawal N, Pallos J, Rockabrand E, Trotman LC, Slepko N et al (2004) SUMO modification of Huntingtin and Huntington's disease pathology. Science 304(5667):100-104

31. Yau RG, Doerner $K$, Castellanos ER, Haakonsen DL, Werner A, Wang $N$ et al (2017) Assembly and function of heterotypic ubiquitin chains in cellcycle and protein quality control. Cell 171(4):918-33.e20

32. Hakim-Eshed V, Boulos A, Cohen-Rosenzweig C, Yu-Taeger L, Ziv T, Kwon YT et al (2020) Site-specific ubiquitination of pathogenic huntingtin attenuates its deleterious effects. Proc Natl Acad Sci U S A 117(31):18661-18669

33. Terman A, Brunk UT (1998) Lipofuscin: mechanisms of formation and increase with age. APMIS 106(2):265-276

34. Hohn A, Jung T, Grimm S, Catalgol B, Weber D, Grune T (2011) Lipofuscin inhibits the proteasome by binding to surface motifs. Free Radic Biol Med 50(5):585-591

35. Kakimoto Y, Okada C, Kawabe N, Sasaki A, Tsukamoto H, Nagao R et al (2019) Myocardial lipofuscin accumulation in ageing and sudden cardiac death. Sci Rep 9(1):3304

36. Kakuda N, Miyasaka T, Iwasaki N, Nirasawa T, Wada-Kakuda S, TakahashiFujigasaki J et al (2017) Distinct deposition of amyloid-beta species in 
brains with Alzheimer's disease pathology visualized with MALDI imaging mass spectrometry. Acta Neuropathol Commun 5(1):73

37. Takaishi M, Makino T, Morohashi M, Huh NH (2005) Identification of human hornerin and its expression in regenerating and psoriatic skin. J Biol Chem 280(6):4696-4703

38. Makino T, Takaishi M, Toyoda M, Morohashi M, Huh NH (2003) Expression of hornerin in stratified squamous epithelium in the mouse: a comparative analysis with profilaggrin. J Histochem Cytochem 51 (4):485-492

39. Wu Z, Meyer-Hoffert U, Reithmayer K, Paus R, Hansmann B, He Y et al (2009) Highly complex peptide aggregates of the S100 fusedtype protein hornerin are present in human skin. J Invest Dermatol 129(6):1446-1458

40. Fleming JM, Ginsburg E, Oliver SD, Goldsmith P, Vonderhaar BK (2012) Hornerin, an $\mathrm{S100}$ family protein, is functional in breast cells and aberrantly expressed in breast cancer. BMC Cancer 12:266

41. Choi J, Kim DI, Kim J, Kim BH, Kim A (2016) Hornerin Is Involved in Breast Cancer Progression. J Breast Cancer 19(2):142-147

42. Fu SJ, Shen SL, Li SQ, Hua YP, Hu WJ, Guo B et al (2018) Hornerin promotes tumor progression and is associated with poor prognosis in hepatocellular carcinoma. BMC Cancer 18(1):815

43. Gutknecht MF, Seaman ME, Ning B, Cornejo DA, Mugler E, Antkowiak PF et al (2017) Identification of the S100 fused-type protein hornerin as a regulator of tumor vascularity. Nat Commun 8(1):552

44. Romero P, Obradovic Z, Li X, Garner EC, Brown CJ, Dunker AK (2001) Sequence complexity of disordered protein. Proteins 42(1):38-48

45. Dyson HJ, Wright PE (2005) Intrinsically unstructured proteins and their functions. Nat Rev Mol Cell Biol 6(3):197-208

46. Cleary JD, Pattamatta A, Ranum LPW (2018) Repeat-associated non-ATG (RAN) translation. J Biol Chem 293(42):16127-16141

47. Kosugi S, Hasebe M, Tomita M, Yanagawa H (2009) Systematic identification of cell cycle-dependent yeast nucleocytoplasmic shuttling proteins by prediction of composite motifs. Proc Natl Acad Sci U S A 106(25):10171-10176

48. Nguyen Ba AN, Pogoutse A, Provart N, Moses AM (2009) NLStradamus: a simple Hidden Markov Model for nuclear localization signal prediction. BMC Bioinformatics 10:202

49. Lin JR, Hu J (2013) SegNLS: nuclear localization signal prediction based on frequent pattern mining and linear motif scoring. PLOS ONE 8(10):e76864

50. Pearton DJ, Dale BA, Presland RB (2002) Functional analysis of the profilaggrin $\mathrm{N}$-terminal peptide: identification of domains that regulate nuclear and cytoplasmic distribution. J Invest Dermatol 119(3):661-669

51. Lu J, Wu T, Zhang B, Liu S, Song W, Qiao J et al (2021) Types of nuclear localization signals and mechanisms of protein import into the nucleus. Cell Commun Signal 19(1):60

52. Xie H, Vucetic S, lakoucheva LM, Oldfield CJ, Dunker AK, Uversky VN et a (2007) Functional anthology of intrinsic disorder. 1. Biological processes and functions of proteins with long disordered regions. J Proteome Res 6(5):1882-1898

53. Huang KY, Su MG, Kao HJ, Hsieh YC, Jhong JH, Cheng KH et al (2016) dbPTM 2016: 10-year anniversary of a resource for post-translational modification of proteins. Nucleic Acids Res 44(D1):D435-D446

54. Kollipara L, Zahedi RP (2013) Protein carbamylation: in vivo modification or in vitro artefact? Proteomics 13(6):941-944

55. Farrer M, Stone J, Mata IF, Lincoln S, Kachergus J, Hulihan M et al (2005) LRRK2 mutations in Parkinson disease. Neurology 65(5):738-740

56. Karczewski KJ, Francioli LC, Tiao G, Cummings BB, Alfoldi J, Wang Q et al (2020) The mutational constraint spectrum quantified from variation in 141,456 humans. Nature 581(7809):434-443

\section{Publisher's Note}

Springer Nature remains neutral with regard to jurisdictional claims in published maps and institutional affiliations.

Ready to submit your research? Choose BMC and benefit from:

- fast, convenient online submission

- thorough peer review by experienced researchers in your field

- rapid publication on acceptance

- support for research data, including large and complex data types

- gold Open Access which fosters wider collaboration and increased citations

- maximum visibility for your research: over $100 \mathrm{M}$ website views per year

At BMC, research is always in progress.

Learn more biomedcentral.com/submissions 